\title{
21. Learning How to Relate: Notes of a Female Anthropologist on Working with a Male Fieldworker in Vanuatu
}

\author{
Sabine Hess
}

In 1999 I visited Vanua Lava for three weeks to find a fieldsite for my doctoral research. Eli Field had been recommended to me as an experienced fieldworker from the Vanuatu Cultural Centre (VCC). During this first trip I was adopted by Eli Field as a daughter and my new family, his wife Joana and their five sons and two daughters, looked after me. Eli helped improve my Bislama by speaking what seemed to me in hindsight almost non-stop and high speed. My mother, Joana, took me to the creek to wash, showed me how to grate coconuts and how to sit properly. It was a crash course in village life in Vanuatu. I was also introduced to other villagers and the chiefs; and I managed to record a few stories.

In October 2001, almost two years later I returned, this time to stay for one year to undertake doctoral research in anthropology for which I had secured funding from the Australian National University (ANU). Again, Eli Field and Joana welcomed me as their daughter. During the following year I learnt what exactly this entailed: how I was supposed to behave and also what I could get away with due to my being a different kind of daughter, for example living in a house by myself.

From anthropological literature like Charles Briggs' (1986) book Learning How to Ask (1986) we learn crucial lessons on how important it is to pay attention to meta-communicative aspects of the culture we study: how people talk to each other in different situations and social settings, what questions one may ask of whom, and which topics are left out. Coe's (2001) article 'Learning how to find out', a kind of follow-up to Briggs, makes us aware of different kinds of knowledge. Inspired by Bloch (1993), she distinguishes three kinds of knowledge: practical knowledge (everyday tasks, cooking, washing), specialised knowledge (carpentry, weaving), and knowledge focused on history (family and chiefly genealogies, the history of a town) (Coe 2001: 403). Furthermore, what people consider important knowledge may differ from what the anthropologist considers important knowledge.

Like Coe, I had read Briggs before going to the field, and I was indeed paying attention to people's meta-communication. How people interact with each other is dependant on three structuring social categories: kinship, gender and 
generation. While I recognised these, I also have to admit to trying to partially circumvent what I learnt. I wanted to ask questions despite these restrictions. This of course proved unsuccessful but made for a good lesson. I learnt that the basis for learning how to ask, or meta-communication, is learning how to relate.

In what follows I will trace my own (at times steep) learning curve through discussion of some anecdotes from my fieldwork. I can only speculate on how Eli Field experienced these incidents and what he may have learned from them. I hope that he will have the chance to present his views on the progress of our cooperation and relationship. If he does so I think the reader or listener will gain more than the sum of the two parts.

\section{Father and fieldworker; daughter and guest}

Not long after my arrival a death occurred in the neighbouring village, Vatrata. Arrangements were made for everyone to go, except my mother Joana, who was to stay behind to look after me. When I realised what was happening in the general rush for departure I caught Eli and said that I wanted to come too, that in fact I needed to go because this was part of my work. At first he seemed sceptical whether I could walk the distance through the bush, crossing three creeks on the way, as quickly as required but eventually he agreed that I could come. I, on the other hand, was surprised that he had seemingly tried to exclude me from ritual activity which - surely as an experienced fieldworker he should know-would be important for me to record.

So what happened? The only explanation I had was that he thought of me as a daughter and guest and therefore was more concerned with my wellbeing than with my task as a researcher. Up to my arrival his role as a fieldworker had been very much defined by the relationship between him and the VCC in Port Vila, and not so much by the relationship between him and another researcher living in his own village.

As already mentioned, being adopted into a kin network meant that people knew how to relate to me. I, in turn, had to learn how to relate to them. Interaction in cross-sex relationships are imbued with restrictions of all kinds. This is particularly true for a father-daughter relationship, which is marked by mutual respect and partial avoidance, for example we may not look at each other for prolonged periods of time. Doing interview-based research this aspect was difficult to remember as the Western style of communication is keeping eye contact to signal attentive listening and interest.

In addition to this problem I was also faced with restriction on the topics I could discuss with Eli. Topics related to women and sexuality were taboo. Any 
suggestion to temporarily 'forget' our father-daughter relationship for an hour or so and work as fieldworker and anthropologist were unacceptable, unthinkable. A division of work and private life, from kinship as the way of relating, was impossible. Initially, this caused quite some frustration on my side. On a number of occasions I mentioned that if there ever was another anthropologist coming he or she should be adopted as Eli's sister's child because this is the least restrictive relationship in terms of flow of knowledge. Eli seemed hesitant and commented with a 'yes, maybe' rather than 'yes, what a good idea'. Maybe such a relationship would pose a whole new set of problems.

\section{Key informant and gatekeeper}

The special situation and good fortune of the existence of the Vanuatu fieldworker system practically delivers us a key informant at our doorstep, or rather us to theirs. And, indeed, fieldworkers are very valuable to us and often our work would not flourish or be possible without them. However, there are also some challenges. Talking to other researchers working in Vanuatu we frequently arrived at the topic of the fieldworker as key informant and the power he or she has. Because of their specific knowledge, their practice at articulating it, and their initial exclusive access to the freshly arrived researcher, they are simultaneously key informant and gatekeeper. Fieldworkers can be gatekeepers in two related ways. They control the flow of resources and of knowledge. I have heard stories where the fieldworker tries to keep the researcher and the resources that come with him or her to the benefit of his family only. This is understandable from a local perspective. But as a fieldworker - and maybe this has been covered in the fieldworker-workshops already - assistance to researchers means also assistance in access to other people, even people that the fieldworker may not agree with. If this means that the researcher gives some rice to someone else for a change, then so be it!

A fieldworker is more than an ordinary member of society. He or she is (or should be?) also a mediator enabling access to knowledge. Researchers usually come to find out information about a specific topic. They would like to talk to various people, not just one or two. While the fieldworker may be an expert, other people in the community may also have valuable knowledge to contribute. The great strength of the fieldworker is that he or she knows whom to ask for specific knowledge. This is usually straight forward if the person in question is a relative of the fieldworker. But if the fieldworker has no obvious family ties to this other person, or there are personal tensions between them, it is, in my understanding, the task of the fieldworker to find a way to make this contact possible, even though his or her own proper way of behaving would be avoidance. 
In this last section which was addressed as much to fieldworkers as other audiences, my own bias towards putting research first, before kinship and rules of sociality became apparent. If I was doing research in a place that had no fieldworker system this expectation may never have occurred. To me, fieldworkers are cultural brokers who more or less understand the principles (or ideology?) of research as a worthy end in itself and can mediate or switch between the two cultures and their expectations. My assumption might be wrong, or may be asking too much. Is it really possible for a fieldworker to push his or her relationships into the background for someone else's research with a slim chance of usefulness to locals? Maybe every person can answer this for him or herself. I wonder what the official VCC's advice would be?

At this point I would like to tell an anecdote of my research as a gentle reminder to other researchers to respect restricted knowledge: Together with my colleague Sophie Caillon we had elicited a restricted story about the creation of taro gardens from two of our uncles. No need to say Eli Field, was furious. To us the story was significant as it allowed us to create a theoretical link between taro and people in a new way. But other than that, we could see nothing in the story that was particularly worthy of secrecy, although it was highly amusing. I tried to explain the importance of the story to our work to Eli, but he threatened to withdraw from the research altogether if I continue to seek this kind of knowledge. I was furious too and for about three weeks we hardly talked to each other. These weeks he also used to prepare every person in the village about what kind of information they were not allowed to pass on. I had to give in so that I could continue my research.

Initially it felt like defeat, but I came to understand his point of view. To me this story was 'just another story', one of many I recorded. To Eli Field and to many others, if women know the story in detail the existence of the irrigated taro gardens would be threatened by drought. So my knowledge of the story was a potential threat to people's survival on the island. Who am I to say whether this is 'real'? No research is that important! And I did get my PhD without this story after all. So, here is a plea to all researchers: don't lose perspective in the name of science and respect the limits of people you work with.

\section{Father and daughter}

What would you do if an anthropologist turned up at your doorstep? One must not forget that I had more time and resources to prepare for this encounter than Eli Field. What had he known about anthropology or the strange questions these people ask about the most obvious things? I assume that his learning curve was at least as steep as mine and that he has some pretty good anecdotes and 
insightful observations about our time together to tell, too. May be he can give some hints to fieldworkers on 'what to expect' and some advice to researchers on the dos and don'ts of fieldwork.

Over the year that I lived on Vanua Lava I think we learned to live and work together and respect each other as father and daughter and as fieldworker and anthropologist. Because I learnt how to relate I learnt how to ask. And I noticed changes in Eli Field's relating and responding too. While I learnt how to ask properly, Eli learnt that my questions where different from the ones he was used to from his normal interlocutors. Initially I asked about incidents I observed to learn about the principles of behaviour. For example I would ask: Why did you give so-and-so some money? Coming from some other person in the community this question could be understood as a kind of social control, a criticism, or a demand, to name a few possibilities. The answer for this person would have been, a justification and not so much an explanation. In the beginning I had trouble understanding Eli's response because they were often more justification than explanation. After some time of getting used to what must have seemed the most obvious questions his answers became less defensive and more explanatory, not so much concerned with personal detail (burdened with a reluctance to reveal) but more abstract, trying to convey the principle. Eli learnt very quickly to respond to my expectation of this kind of answer. This transition, I think, was not easy. As I became more familiar with the principles, however, I wished more for the 'normal' kind of answer. Once I learnt to use questions as the locals did, my expectations of an answer became mixed. Sometimes I wanted an explanation, sometimes just an 'authentic' kind of answer. And in Eli's particular case I sometimes wanted to see how the justification was framed as an explanation. Eli in turn became competent at distinguishing what I was after and giving answers that he thought appropriate. We had, after all found a kind of middle ground where I could ask questions that were within the limitations of a father-daughter relationship, and he could answer in a way that would not be understood as gossip. With this mutual understanding of appropriateness, sensitive topics, such as land rights, could be discussed using particular people's situation as a 'case study' rather than as a claim to land or a doubt of their rightful ownership.

To conclude I have to say that despite the restrictions and challenges that such a relationship poses I am glad to be in a father-daughter relationship with Eli Field because of the respect and protection it affords. I think his suggestion of female researchers working with female fieldworkers, and male researchers working with male fieldworkers where possible is a good idea in some cases. Another consideration might be how the relationship and the work would be affected if the researcher would be adopted into the same generation as the fieldworker, for example as a sister or brother, something fieldworkers expecting a researcher may want to think about. 
I doubt whether there really would have been a shortcut for acquiring this kind of embodied knowledge of how to relate beforehand. Relating to people is dependant on many things - words like sympathy, sense of humour, understanding, and sincerity spring to mind, not really something one can practice before one actually gets there. As advice for researchers I would say: try to work with people you like, and think of making mistakes as part of your method.

I would like to, again, thank Eli Field for his support and conclude with his summarising comment about our (working) relationship on my day of my departure: we had a good hard time.

\section{Postscript}

At the conference this paper was presented for me by my former supervisor Margaret Jolly, which I was delighted to hear. Weeks before I had first asked the linguist Catriona Malau if she would read a paper for me at the conference. Catriona and I had been working together on Vanua Lava, so she seemed an obvious choice. But since then she had become my 'sister-in-law' because she had actually married Eli Field's son Armstrong Malau. When we met in Amsterdam three weeks before the conference she read the paper and realised that it would be impossible for her to read it at the conference since she cannot say Eli's name. She stressed that for her the in-law-relationship is a very real one, not a fictitious one like 'adopted' researchers might have. As a daughterin-law she could clearly not read a paper on a daughter-father relationship. I guess this anecdote of my omission and her position, again, emphasises how important it is to consider relating in the right way first (even at an international conference) - before doing anything else.

Unfortunately Eli Field did not arrive in Port Vila in time for the conference, so his side of the story is still missing.

\section{References}

Bloch, Maurice, 1993. The uses of schooling and literacy in a Zafimaniry village. In Cross-cultural Approaches to Literacy, ed. Brian Street, 87-109. Cambridge: Cambridge University Press.

Briggs, Charles L., 1986. Learning How to Ask: A Sociolinguistic Appraisal of the Role of the Interview in Social Science Research. Cambridge: Cambridge University Press.

Coe, Cati, 2001. Learning how to find out: theories of knowledge and learning in field research. Field Methods 13, 392-411. 